\title{
Motherhood, medicine and cancer
}

\author{
Hannah Feiner MD, Sunit Das MD PhD, Suzanne Turner MBS MD, Kaitie Turchin MD
}

Cite as: CMAJ 2021 September 20;193:E1459-61. doi: 10.1503/cmaj.210901

H annah Feiner, a 30-year-old family physician in her first year of practice, underwent magnetic resonance imaging (MRI) to investigate new migraine headaches. The scan showed a brain tumour in her right frontal lobe. A week later, Dr. Sunit Das, a neurosurgeon who works in the same teaching hospital as Dr. Feiner, performed a craniotomy. Specimen pathology showed a grade 2 astrocytoma. Hannah was told that the average life expectancy of someone with this tumour was 10 to 15 years.

\section{Patient's perspective}

Nine months after I was diagnosed with an astrocytoma, my oncology team gave me their blessing to try to conceive. I nearly skipped to the laboratory for my prepregnancy blood work. My pixie cut hid my craniotomy scar. My handbag held my laboratory requisition, a snack for my afternoon clinic and a draft of the seating chart for our wedding. The green vinyl chair was almost comfortable, but I could feel a bruise starting as the needle stung my inner elbow.

I was followed through my pregnancy by my oncology team and a high-risk obstetrician who specializes in patients with brain tumours. The day before I went into labour, I was coteaching one of my weekly sessions on the art and science of clinical medicine with Dr. Das. The course was a highlight in my role as a clinician-teacher. Dr. Das was assigned to my group of first-year medical students to provide patient context to the neurologic exam. Before the students arrived that morning, he asked me if they knew. They did not. As Dr. Das brought us to the trauma and neurosurgery floor of St. Michael's and introduced the students to patients with brain cancer who had obvious cranial nerve deficits, I didn't reflect on the juxtaposition of malignant brain tumours and the new life inside me. I didn't need to. I knew I had Dr. Das's support.

The day my daughter, Julia Rose, was born, giddy March snowflakes danced outside my postpartum room. I'd only managed 2 hours of sleep after preterm labour and an urgent cesarean delivery. Julia wore a hospital linen swaddle until my brother and sister-in-law brought newborn clothes. My parents brought fresh fruit and Scrabble. My in-laws brought homemade dinner. The new grandparents took turns holding Julia, warm in my mother's just-knit blanket.

Julia made a lovely, constant companion. She slept through restaurant dinners, car trips and oncologist appointments. When we learned that my first MRI after my pregnancy showed my tumour was stable, my "scanxiety" didn't dissipate. Anxiety gave way to guilt when I took my sweet daughter out of her carrier to breastfeed. The relief of my partner, Diego, did not reassure me. My ruminations played on repeat as Julia and I logged kilometers of neighbourhood sidewalks. Tumour degeneration. Uncertain prognosis. Motherless daughter. Spring turning to summer and mom-and-baby yoga didn't help.

I turned to therapy. I pushed our canopied stroller to a psychologist's midtown office. After a few sessions, she suggested mindfulness would be more effective than talk therapy for my cancerinduced distress. My mother-in-law kept Julia on Wednesday afternoons while I attended a mindfulness-based stress reduction course. It changed my life. I shifted from fanning the flames of my worries to learning to live with them. I learned to track down guilt and anxiety in my body and breathe out their knotted ache instead of playing the same terrifying thought on repeat. I practised breathing with Julia's little body as an extension of my own. ${ }^{1}$ I practised noticing each small blessing: Julia's smiles and finger grabs, and Diego's arms around my shoulders. I approached surveillance MRIs with more equanimity than anxiety.

I began part-time work when Julia was 4 months old. I was grateful for the daily sense of accomplishment that patient care provided. Resuming my professional identity led to an integrated self-concept: physician, brain cancer patient and mother. Diego and I planned a second pregnancy. Julia and her sister Alice are now 7 and 4 years old, their photos framed on my office wall and with me when I go to my appointments with Dr. Das.

\section{Neurosurgeon's perspective}

I first met Hannah in our emergency department, accompanied by her partner, Diego. I had been told by my residents that she was one of our family doctors and that her father-in-law was a surgeon in the community. Hannah had been sent to the emergency department after an MRI, prompted by new headaches, had shown a brain mass.

Hannah, Diego and I spoke about the imaging findings and next steps. I try to be earnest in these first meetings, honest about what I am seeing and about the seriousness of it. To be having this conversation with a fellow physician - a colleague only made getting the words right seem even more critical.

All went well with surgery. The pathology confirmed what I had suspected from the MRI, that Hannah had a low-grade glioma. We talked again about what this diagnosis would mean for 
her, for Diego and for their future. I explained that she would be living with a disease for which the goals of treatment would be to improve on what would be expected without intervention. We would do what we could to control the progression of her tumour and keep her well. I told her that we would arrange for her to meet with my partners on the treatment team; at some point, she would require chemotherapy and radiation, and perhaps more surgery. Our treatments would push forward the time before the tumour became a greater threat to her.

We would not be able to cure her.

Hannah and Diego assimilated this news with grace. We began the ritual of follow-up: the steady march toward the next quarterly scan that always somehow comes sooner than it seems it should, the limbo of waiting for the results, for which I know my patients hold their breath and which never come quickly enough. Hannah, Diego and I slipped into a rhythm: our clinic visits every 3 months, seizures well controlled, no new symptoms, the MRI not showing any new signs of concern, more and more plausible hope that tomorrow could hold the same promise as today.

Then came the day that Hannah and Diego spoke with me about their wishes to start a family. Hannah had been discouraged by conversations that she had had with other members of her care circle who told her that the data raise concerns that pregnancy can be a driver of glioma progression, that becoming a parent while knowing that one has a fatal disease holds with it severe moral demands.

I told her that both issues were real. That none of us are able to do anything more than hope that we will be here tomorrow. That while her mortality might have a name to it, it was no different than the reality that all of us live with each day. That I couldn't offer my daughter any greater promises or guarantees than she would be able to offer hers.

I've now known Hannah for nearly a decade. I've since had another child, a son; Hannah and Diego now have 2 children. She has become a part of my life, crossing the blurry line between patient and friend as I suspect many long-term patients do. I have refrained from friending her on Facebook but look forward to the pictures she shares of her growing kids at our appointments. And I hold my breath each time I pull up her new scan.

\section{Colleague's perspective}

Hannah and I met in medical school, and I was excited when I started my first staff position and found out that she was also doing primary care obstetrics with the family practice team I was joining. She became that "phone-a-friend" - the lifeline you need when you first start practice, and especially value when you're up in the middle of the night with a patient having a difficult labour.

When Hannah's cancer was diagnosed, she approached it as she does the care of her patients - with honesty. She was open and clear with her colleagues about the nature of her cancer, so there would be no speculation. She was clear about her prognosis.

There was the complexity of having an illness and planning a family. I remember the judgments lurking behind our colleagues' eyes; why would someone have a child when they have cancer? One day, after family medicine rounds, Hannah had left for clinic and I was pulled into a small group of colleagues, all pregnant or mothers of young children. One asked indignantly, "Is it true, is Hannah pregnant?" When I responded that she was indeed due in the early spring and that I was excited for her, the colleague rushed ahead, "But, what if she dies before her children are grown?" Another colleague spoke up, "Is she planning on returning to medicine? I wouldn't. I think she's selfish if she doesn't just dedicate her time to her kids." I tried to respond in a way that supported Hannah's decision, but I struggled in considering my own mortality and what it would mean for my children if I died. I didn't initially share my thoughts with Hannah; I was embarrassed by what she might think of my discomfort.

On the first warm day of maternity leave, Hannah and I decided to wrangle our newborns and try to eat our lunches outside. It turned into a comical task as we tried to ensure the babies were out of the sun, prevent our food from blowing away, and eat one-handed while bouncing the babies with the other. As with those middle-of-the-night debates about complicated patients, we were each other's "phone-a-friend" as we navigated motherhood. Watching Hannah with Julia, I couldn't imagine how anyone wouldn't understand Hannah's decision to have a child. Julia was a loving child with a bright smile, and the joy in Hannah's eyes when she changed a diaper or fed Julia lit up the room. I eventually told Hannah about the hushed conversation with our colleagues who questioned why she would have children when she had a cancer diagnosis. Witnessing Hannah's experience with cancer and motherhood, and watching her with Julia, changed how I counsel my patients. I strive to support patients with chronic illness. I specifically ask them if they are trying to conceive or have thought about having a family. I used to shy away from those questions for fear of how I would answer if they told me they wanted to conceive; I was concerned that I might express my own discomfort. I am now able to discuss openly the difficulties that might arise related to conceiving, the impact of medications on pregnancy, prognosis and the possibility that they might have a limited time with their child. But I also provide hope. I tell them of my friend and colleague with an illness who chose to have a child. I explain that I am a better physician for having met her and the world is a better place for having her, and that Julia showed us the joy that came from Hannah's decision.

\section{Friend's perspective}

Hannah and I were roommates when she received her diagnosis of brain cancer. A migraine headache for the first time at age 30 years. The urging of the family friend, an otolaryngologist, to get an MRI "just to be sure." The diagnosis received in the middle of her family medicine clinic. The email we - her family, her friends, her world - all received.

In that diagnosis there is sadness, hopelessness, despair, injustice and anger. And yet, from the beginning, all I saw in Hannah was determination, equanimity, acceptance, hope, action, honesty and love. 
I see her in a lovely silk head scarf, brunching on the rooftop deck of her condo the day after being discharged from her first surgery.

I see her in a pub, out for drinks after an especially rousing recreational soccer game one summer evening, awaiting her pathology results. Telling us the ramifications of a grade 2 versus grade 3 tumour. So matter-of-fact, so open, so honest. Her mantra was "Let it be a 2, let it be a 2, let it be a 2," and so that became our mantra. We held our collective breaths, and when we found out it was a 2, we all turned to her and exhaled.

I hear her telling us that her prognosis had an average survival of 10 to 15 years. I did the calculations in my head. But she was young, healthy and strong, new research would provide more treatments in the years ahead and we'd have her with us into our golden years and beyond.

I see Hannah with Julia in the first year after her birth. They joined us for pedicures, heart-to-hearts over coffee, cottage trips. Not only did she continue exactly as she was before her diagnosis, she somehow accomplished this while being a new mother as well.

I remember on one of our walks, she told me she wasn't afraid to die but that she was afraid to leave her daughters. It was the only time I had seen her cry since her diagnosis. I remember the solace she took in her therapist's reassurance that those first 5 years of a child's life are the critical ones.

I feel so privileged to walk beside Hannah in this journey of life. She has evolved as a mother, friend and physician in ways that most of us can only aspire to in our lifetimes. My beautiful friend has taken a diagnosis that weakens one's body and alchemized it into one that strengthened her soul.

\section{Reference}

1. Kabat-Zinn J. Full catastrophe living: using the wisdom of your body and mind to face stress, pain, and illness. New York: Bantam Books; 2013.
Competing interests: Sunir Das reports grants from the Canadian Institutes of Health Research, the Province of Ontario, Alkermes, Medicenna and Abbvie, as well as royalties from the Oxford University Press, outside the submitted work. He also reports payments from the Congress of Nerological Surgeons, the American Association of Neurological Surgeons, the Society for Neuro-Oncology, the Subcortical Surgery Group and Medexus, outside the submitted work. No other competing interests were declared.

This article has been peer reviewed.

Affiliations: Family and Community Medicine (Feiner) and University of Toronto (Das), St Michael's Hospital, Toronto, Ont.; Family Medicine (Turner), McMaster University, Hamilton, Ont.; Palliative Care (Turchin), Unity Health Toronto; Family and Community Medicine (Turchin), St. Joseph's Health Centre, Toronto, Ont.

Content licence: This is an Open Access article distributed in accordance with the terms of the Creative Commons Attribution (CC BY-NCND 4.0) licence, which permits use, distribution and reproduction in any medium, provided that the original publication is properly cited, the use is noncommercial (i.e., research or educational use), and no modifications or adaptations are made. See: https://creativecommons.org/ licenses/by-nc-nd/4.0/

Correspondence to: Hannah Feiner, hannah.feiner@utoronto.ca

360 Cases is a new type of Practice article that highlights the interpersonal and systemic aspects of health care that are seldom discussed in other Practice articles. Each comprises a brief case summary, followed by personal reflections from 2-4 people involved in the clinical encounter. One author must be a patient, family member or caregiver; the other authors may be anyone involved in the encounter (i.e, physicians, nurses, social workers, dietitians, etc.). For more information, see https://www.cmaj.ca/submission-guidelines or contact Victoria Saigle (Victoria.saigle@cmaj.ca). 